\title{
Study on Governmental Policy Marketing Mechanism
}

\author{
Preng-Nien $\mathrm{Hu}$ \\ Department of Public Administration \\ Nanfang College of Sun Yat-Sen University \\ Guangzhou, China
}

\begin{abstract}
The relationship between the government and the media is mainly to promote its policy philosophy and objectives and to make the policy can be implemented smoothly. In today's information age, the government must contact with the media and other organizations to understand that the media is a journalism business. It is shouldering the mission of disseminating news and culture to shape the socialization of politics. It is a tool for social education. It supervises the normal development of democratic and legal society and maintains good customs and social atmosphere. It also has the power of public opinion sanctions what are collectively referred to as the social responsibility of journalism. In view of this, the government must contact and operate with various media (including nongovernmental organizations) to communicate and persuade policy initiatives that have good law and good intentions through traditional or online media channels. The interaction between them must be closely linked. At the same time, the government must make good use of opinion leaders, non-governmental organizations and other forces to jointly participate in monitoring public opinion and guide the correct direction of public opinion. The government should also promote relevant policies and programs through relevant charity activities to influence the public's point of view and then make them support government policies with actual actions.
\end{abstract}

Keywords—policy marketing; government public relations; agenda setting; Tacitus effect

\section{INTRODUCTION}

The government's implementation of public policies must not only closely and positively interact with the environment, but also need to pay attention to the rationality and feasibility of policy plans and business planning content in order to win the approval and support of the majority of the public.

According to scholar Zhang Shixian, the output of the executive organ of a policy depends on the reciprocal effect between the ability of policy's regulation or structure and the political process: first, if a policy can't be exhaustively regulated or well-structured by itself and also can't arrange various resources and assign executive organs and personnel, then it will depend on executives seeking political support at different times. Second, preparing the exquisite policies above to provide detailed policy directives and policy resources, then use them to buffer short-term focus of public opinions and promote desired behavioral adjustments. (Lin Shuibo, Zhang Shixian, 2011:285) Because the government is in a special position of social administrators and public power users, its behavior and information are authoritative and socially important. Based on this, it is an important source of information for the media. From the perspective of government public relations, it is an important activity to establish a healthy government image through publishing public information (Liao Weijian: 2015:119), especially because that the release of information needs to rely on the cooperation of the media.

The government communicates through the dissemination of media and convinces the public to identify and accept the policy program. Therefore, the media is a necessary condition for government public relations. The media has specific social functions, including environmental supervision, reflection of social reality, dissemination of social culture, entertainment and so on. After observing the government's public relations, the media has the following five positive effects: information release, public opinion reflection, setting of government issues, public opinion formation and feedback, and government image formation. Therefore, the relationship between the media and the government is very close. Government agencies should be good at with and treat and control the media to promote policy marketing in order to strengthen public awareness. And then the government can gain the support from the majority of people and enhance the effectiveness of policy implementation. However, there are still deficiencies in the communication between the government's public relations departments (news spokesman or news contacts) and the media. This paper tries to put forward a specific interactive mechanism to make government policy programs take advantage of the media in the marketing process to make up for their shortcomings and improve the performance of policy marketing, as shown in "Fig. 1". 


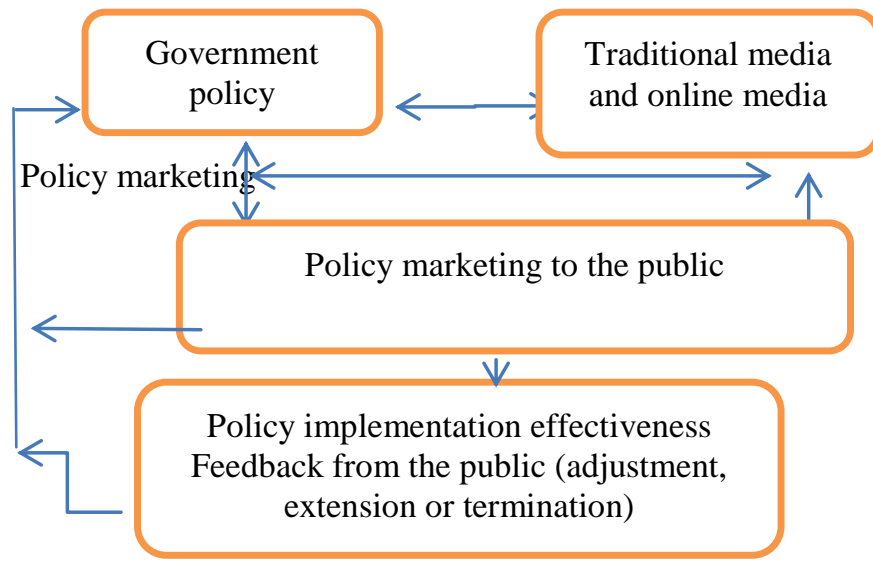

Fig. 1. Interaction between the government, the media and the public.

${ }^{\text {a. }}$ Sources of data: The author organizes himself

The data shows that the government must cooperate with the media for policy marketing and disseminate relevant information through the press release channel of the media. The public's satisfaction with the policy should be continued, adjusted, or terminated after the government's public opinion surveys.

\section{THE IMPORTANT INFLUENCE OF THE MEDIA IN THE POLICY MARKETING PROCESS}

Modern governments have entered the era of economic globalization and social information. The public relations work of the government is faced with many new changes and challenges, especially in face of the changes in the system and functions of public relations media, the public relations personnel of the government must change the old thinking and methods and respond to the media with new ideas, attitudes, and actions. When formulating or promoting a policy, it is necessary for the government to carefully consider the needs of the public, including whether can obtain their support and cooperation, whether there are complete supporting measures to do policy marketing to not only improve the performance of the policy but also promote the image of the government.

The role of the mass media is to play this important function, which already highlights the inextricable relationship between the government and the media and the public. The mass media has played an important role in this, and it has already highlighted the indispensable relationship between the government and the media and the public. Based on this, the government needs to use the media and multiple powers to promote policies, play a guiding role and change paradoxes and create favorable conditions for the government. However, the current government is faced with a highly unpredictable and uncertain environment. It is necessary to maintain close contact with the media to observe and coordinate with each other so as to prevent public crisis events from causing negative public opinion effects. Once the government handles it improperly, its top leaders and relevant cadres are subject to punishment. However, despite the fact that our governments at all levels have issued many contingency plans, the handling of crisis incidents is still impossible to implement and the situation has become irrelevant. After reports from the traditional media or new media, it has caused serious damage to the government's credibility and image, which has made people generally feel the "trust crisis" of the government. Therefore, the relationship of the media in Figure 1 above is linked and influenced.

To reverse this trend, the government must set aside the past 'from above to below ' mode of transmission. The process of government policies' dissemination to the public through traditional media or new media is no longer the mode of dissemination of the bureaucratic system in the past. Instead, it is a flexible, multi-dimensional Online and offline cooperation mode of integrated communication technology to report and communicate information to promote and promote policies. This is the characterization of an e-smart government, which is also the new mode of interaction between the government and the media.

\section{POLICY MARKETING}

Scholar Kotler once defined marketing: Marketing management is demand management (Kotler, 1997: 19).It is the opinion of the current general public management school that the customer-oriented business philosophy is the presentation of marketing concepts aimed at achieving the goal of organizational profitability.

Another scholar, Keith Snavely (1991), pointed out that in the process of formulating public policies; the government plays a role in providing various public services to the public. Apart from meeting public needs, it can also promote the implementation of policies. However, the organization uses marketing means to achieve the mission objectives. The marketing strategy is a professional skill that must be implemented completely to make policy implementation more smoothly. If the government wants to expand public relations, it is necessary to use various media channels to enable the public to fully understand, and agree with the policy's key goals, directions, and expected benefits, so as to create the public's well-being and further promote their full support and cooperation.

The government's policy marketing center focuses on using the mass media as an agenda setting, adopting a position that is favorable to the government to report and promote the specific contents of the policy plan and guiding the support of the public opinion. Hereby, government policy marketing has the following priorities:

The strategy of striving for customer (public) orientation is not only the consideration relationship between creation and sales, but also to pay more attention to the public's deeper feeling needs and quick feedback to meet their needs. When the public is willing to pay tangible or intangible capital and get the expected results, it can reduce the burden on the government's huge cost expenditure.

When planning policies, the government must engage in market research to identify target groups, organize evaluation and select target markets so that to decide to take no difference or differentiation, or even focus on marketing methods for the 
achievement of 'unresolved treatment' fair marketing performance.

The government implements with the concept of corporate marketing portfolio 4P (products, access, personnel, and promotion). Government marketing products include anything that meets the customer's needs, such as physical plans, services, personnel, organizational experience and so on. In addition to the cost of purchasing goods or services, government prices include non-material factors such as the time that people use the service, and the access includes physical stores, business days, convenience, accessibility and so on. Promotion strategies are often described as persuasive communication and the benefits that customers (the public) have after using government-provided services.

The government marketing function needs to ensure that the marketing performance is evaluated and the adjustment measures are implemented. The procedures are the goal setting, assessment of performance, performance diagnosis and corrective actions.

Before the government's policy plans are finalized, the government's internal project team will first review the proposal, handle a hearing or forum, invite interested parties to attend the meeting to listen to opinions and provide guiding ideas. After finalizing the case, the policy plans were sent to the legislature for deliberation and passed to the media for publishing information. If the policy plans received approval and support from the mainstream public opinion, the policy promotion effect will be significant. On the other hand, if most people are against the policy plans, and they are implemented invalid or biased after a period of time, they must be immediately adjusted, amended or stopped. Therefore, it is necessary to use media policy marketing methods to conduct "Persuade" propaganda to let the people who try to change objections or have no concrete ideas accept the policy concept, and then help the government to implement the policy. In short, the media is the government's propaganda tool, and it is also a weapon to establish and improve the government's credibility and image.

We should establish and improve the mechanism for wide participation of government and people. The government needs to continuously cooperate with enterprises, relevant industry associations or third-party agencies to handle the planning and implementation of policies, and co-ordinate office benefits and other related activities in a timely manner, so that enables government, companies and other third-party agencies to truly integrate into the systems and mechanisms of government policy planning and implementation. And then they can propose specific actions to improve the overall team strength.

In general, customer-oriented services are arguments advocated by the School of Public Management. The relationship between the government and the customer (the public) is the relationship between the subject and the object. The media is also the government's object relations, and it is also an intermediary variable for the government to use communication tools to reach the object. The government must maintain a good relationship with the media because it is a propelling device for the promotion of policy marketing. At the same time, the government also needs to combine and use friendly civil organizations to participate in the planning and implementation of policies. It also needs to reduce cost expenditures and exert high levels of efficiency and effectiveness. The government marketing function needs to ensure the assessment of marketing performance, the implementation of adjustment measures and so on.

\section{The Operating Status of the Media}

The media is the public device of the society. It has the role and status of the government's "fourth right" because it represents the people to exercise the power of supervision; With the development of communication technology, the role and function of the media in government policy marketing has directly or indirectly approached the life circle of the public. As a result, with the rapid development of the Internet (Twitter, Facebook, Weibo, WeChat, etc.), online media has mushroomed and the sudden increase in public demand for news information also requires the media to report quickly. Traditional media is subject to publishing tools which makes its competitiveness worse than new media. So, it needs a transformation operation which is that the traditional media and network new media (network) must cooperate in division of labor, especially for news of major emergencies should be reported by online media first. An in-depth report or commentary on a social event, or news information with nature such as artistic or knowledgeable should be reported through traditional media. Then a complementary relationship can be generated between them. As far as the policy formulation process is concerned, the news media has flourished with the development of the technology era. After all, the importance of news media in policy marketing mainly has the following characteristics:

In policy planning and the formation of issues, the agenda setting of the media can dominate or influence the cognition, evaluation, and behavior of the people. Therefore, the issues reported by the mass media will have an influential role in guiding the public to adopt a position of support or opposition, putting forward opinions on the government appropriately and requesting the government to act or not. Therefore, the government's decision must be based on the majority of public opinion because it can have a decisive influence on the government's decision (Wu Yixuan, 1998: 132 133).

Both the media and the government should build a platform. Then the public can use the platform to express their opinions. (But the opinions should not involve in harming state security, political sensitivity, social morals and manners, personal privacy, etc.)At the same time, the media or the government can put forward opinions on certain topics, guide public opinion towards the set of topics and develop the mainstream awareness and values that are conducive to the government's image public opinion. For the early, middle and late periods of major government policy decisions, they can conduct public opinion surveys to understand public sentiments and gains and losses. This can not only provide (big data) reference for government decision-making, but also allow the media or government to publish the news with the analysis of the public opinion, then they can explain the focus of the issues and solutions and make in-depth communication 
with the public. Therefore, the government must set up a database for collecting and using public opinion as a policy analysis then consider it as a reference for government administration. It is also necessary to fully communicate and cooperate with the media so that the media can fully exercise the function of "supervising" and publicly report existing policy performance so that the government can promptly take appropriate actions on the focus of the issue (e.g., let opinion leaders quickly respond online).

In addition, government policy marketing must have the active involvement of stakeholders and ensure that the government information is public, institutionalized, and transparent. Relevant stakeholders should be able to quickly and accurately share and use information so as to be prompted to understand and agree with the priorities, directions, and budgeting of government administration.

The key to the success or failure of a policy lies in whether the government policy has been communicated during planning and execution and is generally supported by public opinion. If the government wants to get a high degree of public opinion, it must use the power of the media or nongovernmental organizations to cooperate with the propaganda and operation so that let the majority of the public have a good perception of the policy issues. At the same time, public opinion also needs timely feedback to the government in order to make reference to the future political development. All of these need to rely on the high degree of cooperation between traditional media and new media so that let people's recognition of government policy marketing effectiveness high and show the government's specific policy performance.

Creating a new government image requires close cooperation between the media and the government. The government needs to invite various media, companies, or nongovernmental organizations (industry associations, etc.) to participate in the various public relations activities to increase the effectiveness of positive publicity so as to increase the visibility and reputation of the government.

To sum up, the various affairs of the government must be combined with public opinion. In addition to the investigation process and convergence of public opinions, the government also needs to work closely with the media, companies or nongovernmental organizations to publish information through official or private media. At this time, the media plays an intermediary role in the dissemination of information and functions and conveys a decree.

\section{AnAlyse the Practical Operation OF the Media}

The government public relations personnel are in contact with media reporters almost every day because the government needs to provide information for media reporters. Then the media reporters can use the information to publish news and they can have an interdependent relationship with each other. In particular, the sources of information in the current media come from many sources. When the government formulates relevant policies, media reporters may hear the news and ask the government to confirm and explain whether there is such information and its future development direction. At this time, the relevant government departments should openly explain the truth, and they must not hide or say 'no comment' to shirk their responsibility. Instead, the government must maintain the attitudes and positions of fair, reasonable, legal, and compliant to explain the progress and stance of the matter. In short, the government can no longer use traditional methods to require media reporters in a one-way mode to record and play a role as a government propagandist and megaphone. If things go on like this, such news will be rejected by the public and finally resulting in the 'Tashixi' effect.

Because of the need for long-term operations, the news media must accept a combination with certain large commercial interest groups to sponsor advertising funds, so that the hype of news information has to be limited to a certain commercial profit. Due to this, the media can't report news in a fair, objective, pluralistic, charitable, and enlightened view and be flooded with repeated reports of certain social news, or serial broadcasts of variety shows without deep teaching content to cater to the preferences of some grass-roots workers then lose the media to disseminate facts, and promote the function of enlightenment.

Government leaders and public relations agencies must maintain a friendly relationship with media reporters, especially with medium and senior leaders. When a social event occurs, the government can communicate with the media and explain its position so as to obtain its support and cooperation and resolve the crisis. If the government does not establish and manage relations with the media at ordinary times, the media can use the opportunity of some kind of public crisis to report the negative information of the government which will damage the image of the government and lose the trust of the people. At the same time, the media will use various means to request the government to provide first-hand information in the event of major emergencies. However, in the absence of a spokesperson, it may happen that media reporters casually look for people in the government that are not very relevant to this issue. This may lead to deviations from news reports that are far from the truth. In addition, media reporters will raise doubts about the content of press releases provided by the government and seek out and verify information on their own. This ultimately causes differences in the contents of their reports and government press releases and affects the credibility of the government.

Media reporters may often change the route of their interviews or their positions may be mobilized or they may leave jobs for some reason. The relationship between media reporters cultivated by the government in the past will have a disconnected phenomenon. Therefore, it is necessary to reestablish relations and influence business promotion.

The government news units often take a dominant position due to their failure to take the initiative to set an agenda for network information so that the inappropriate network information will be arbitrarily rendered and spread and cause the negative situation of the rumors being spread around. Moreover, some news media reporters reported without thorough investigation causing the pressure of keeping up to date and publishing news for clarification for the government.

Some government press releases are not treated equally and treated equally but are distributed according to the utilitarian 
orientation of their relationship. As a result, other media reporters who were more estranged from the government were dissatisfied and considered that there was 'differential treatment'. Then the objectivity of government news reporting positions will be affected.

The news media reporters may privately asked the government to purchase pages to publish information or request long-term orders for a certain media which caused the government to be overwhelmed. In order to seek a harmonious relationship, they had to cooperate with each other.

News reporters focus on topics such as novelty, explosiveness, uniqueness, and scarcity in their news interview. Therefore, the media may ask about the information of the worthy news and resulting in problems with citations to data sources. As a result, the government PR personnel must provide full, accurate, professional, and prompt news data to meet the needs of media reporters. The government news liaison personnel must often work overtime to complete the task. It can be seen that the media reporters have a staggering amount of news information.

To sum up, the media, depending on their characteristics, have their own operational concepts and directions and government policies must be understood and marketed. In particular, public relations personnel of the government press should maintain a high level of vigilance and agility at all times, send information on certain unforeseen social events to media reporters, treat media reporters with impartiality, selflessness, equality, and reciprocity, and try to provide the information they need. Then the government can track whether the reports of medias are biased and can be clarified and corrected in due course. In peacetime, it is necessary to establish and maintain a good relationship with the top media leaders and media reporters and fully grasp their relevant dynamic information; If there is any change, the government can adjust the personnel and business procedures at any time so as to make information flow smoothly. Then the government can timely guide the media to communicate with its agenda to disseminate information and play the role of equitable reporting.

\section{SPECIFIC WAYS FOR GOVERNMENT TO INTERACT WITH THE MEDIA}

There are several ways for government interacting with the media in the process of policy marketing:

The principle of equality and reciprocity: The government should maintain a good relationship with the media, do not over-dominate and require that non-governmental media must publish information following the instructions of the government. Instead, they should respect the autonomy of the media and allow the media to exercise its functions within the scope of the ordinance. The media should also cooperate with government policies to disseminate and observe the effectiveness of the implementation of policies and do their best to fulfill the basic functions of media supervision.

The government should contact all media reporters regularly or irregularly to promote friendship: For the reasonable needs of media reporters, the government should seek the consent of the leaders to serve as much as possible. If it is an unreasonable request, it should be declined with reasons so as not to break the relationship and deepen the misunderstanding. In addition, the government must pay attention to the deepening of the media interaction system and procedures, including the refinement of the spokesperson system, the quality of media relations and high-quality crisis public relations.

Government public relations personnel should provide information that the media wishes to know at any time: The media reporters need to understand the scope of responsibilities of government public relations personnel so that they may try not to embarrass the government public relations personnel to for information that cannot be provided. Government public relations personnel should master and understand the characteristics and operational processes of the media they are responsible for, as well as the media reporter's preference for news information. For online media reporters, the government should also contact and communicate with them so that when the online media reporters publish their news, they will first obtain government press release data to dominate the Internet public opinions, clarify unauthentic information in time and guide public opinions in the right direction.

Continuously refine and improve the public relations capabilities of government news spokespersons and press contacts: The government should observe and ensure that the current government spokesperson remains on standby throughout the day. However, some government spokespersons or news contacts have caused misconduct due to negligence in the past. And then lose their job because of the loss of government image and reputation. Therefore, spokespersons and contacts must continue training in their positions to improve their ability to respond to the media and strengthen awareness that not to provide information to only a few specific medias. Before news release, news analysis should be done in advance. And they should pay attention to whether the news report content cooperates with other business departments and pay attention to not to disclose information that can't be provided to media reporters. After being interviewed by media reporters, they can't ask to review the scenes of media reporters (Zhu Zhenming, 2004). They should also indeed improve the responsiveness of reporters and ensure the authority of the content of the speech.

Strengthen the analysis and study of media strategies: Well-known publicist scholar Gruning (1991) proposed from the perspective of communication management that public relations work is to assist organizations in accomplishing tasks effectively and in implementing and managing 'two-way symmetrical communication' between internal and external organizations. This work belongs to the organizational decision-making mechanism and must be attached to the management hierarchy (referred to by Yan Guoren, Zhong Weiwen, 1997). Therefore, the government must use the characteristics of the media and its effectiveness to seek strategies for cooperation with each other.

When confronting a crisis, the government must clarify the nature and principles of crisis public relations: The 
government must grasp the principles such as people oriented, opening truth, timely response, undertaking responsibility, sincere communication, system operation, authority verification and so on to handle crisis events and take corresponding countermeasures including: a. Clearing that it isn't important that media is big or small, the important thing is the value of news; b. Actively applying the information mechanism and Actively leading the media; c. To make full use of the advantages of the media, the government can use the media to carry out crisis-reducing public relations efforts to reduce liability so as to reduce criticism and reshape new images under assuming the responsibilities.

\section{CONCLUSION}

The government uses the media to conduct policy marketing and aims to make the public understand the policy objectives, direction, content, expected benefits and so on. Then it can promote support and identity policies, make the implementation of the policy smooth and improve the effectiveness of the policy.

It is the function to propagandize for the government of the media set up by the government. However, for the operational needs of private media, it must strive for commercial advertising to make profits, so that the media can not put the government's entire policy advocacy.

The marketing effectiveness of the policy is related to the establishment of government performance and image. Therefore, government leaders and their public relations personnel must establish and maintain friendly relations with the media so that the media can report useful information for them. However, due to its own characteristics, the media must play the roles and functions of policy monitors. Therefore, it can't fully meet the expectations of the government. This must be understood and recognized. Public relations agencies should also maintain good interaction with the media as much as possible, so that, in a possible and limited scope, the mutual relations between them can be maintained in equilibrium.

The current government must establish and maintain friendly relations with non-governmental organizations or individuals (non-profit organizations, industry associations, opinion leaders, etc.). Then the government can assist government marketing, reduce the cost of resources, improve the efficiency and effectiveness of government administration and appropriately fill the role of relying on a single media channel to obtain information.

As it is now the era of new media, the government itself must continuously and continuously monitor environmental changes. Through research and other methods, the government should collect and analyze information as a reference for decision-making and then take corresponding actions to respond to and meet the needs of the public.

The government's promotion of policy plans requires the cooperation of media (civil organizations) to promote publicity. It is necessary to seek suitable media to disseminate and communicate and to use its professionalism and its internal operations processes, such as deadlines, press releases, topic preferences and so on. At the same time, the government also needs to establish a perfect system of spokespersons and liaisons so that the media can maintain contact and interaction with them at all times so as to achieve mutual benefit and symbiosis.

Government policy marketing does require a diversified cooperation mode of the media (including civil organizations, etc.) because they go deep into the public to understand the lyrics and know the government's policy goals and priorities. Therefore, government leaders and public relations departments must be familiar with the characteristics and functions of the media to integrate them and implement relevant marketing activities to achieve the effectiveness of mutual aid sharing. And the public can also appreciate the good intentions of the government then they are willing to take concrete actions to support and promote the promotion of government policies so as to realize the achievement of the policy goals as soon as possible.

\section{REFERENCES}

[1] Zang Guoren. Zhong Weiwen.1997.Framework Concepts and Public Relations Strategies - Analysis of Using Media Frameworks.Taiwan, China: Advertising Research Volume 9.

[2] Zhu Zhenming. 2004. The way government interacts with the media in the process of policy marketing. Taiwan, China: The Legislative Yuan, Vol. 32, No. 10.

[3] Wu Yizheng. 1998. Viewing the Government's Media Strategy for Public Security from the Role of Mass Media. Taiwan, China: Theory and Policy No. 47.

[4] Lin Shuibo. Zhang Shixian. 2001. Public Policy. Taiwan, China: Wunan Book Company.

[5] Jia Zhongjie. 2012. Administrative Ethics Construction and Public Relations Cultivation. Beijing: National School of Administration Press.

[6] Liao Weijian. 2015. Government Public Relations. Beijing: Renmin University of China Press.

[7] Wang Min, Deng Zhuang. 2012. Public interest: The logic of interaction between the government and the media. Journal of Tianjin Institute of Public Administration Vol.14 No.1.

[8] Wang Shenghua. 2009. Interaction between the government and the media. Journal of the Party School of the Communist Party of China, Vol. 14, No. 3.

[9] Gruning ,J. and L. Gruning 1991.Conceptual Differences in Public Relations and Marketing: The Case of Health Care Organizations, Public Relations Review, Vol.17,No,3,pp.257-276.

[10] Kotler, Philip. 1997. Strategies for Introducing Marketing into Nonprofit Organization. Journal of Marketing, Vol.43,pp.37-44.

[11] Snavely, Keith.1991.Marketing in the Government Sector: A Public Policy Model. American Review of Public Administration,Vol.21,No.4,pp.311-325. 